\title{
PRODUÇÃO ACADÊMICA NA INICIAÇÃO CIENTÍFICA: o Programa Institucional de Bolsas de Iniciação à Docência como lócus de produção do conhecimento
}

\author{
Ivan Bremm de Oliveira' \\ Mariangela da Rosa Afonso ${ }^{2}$ \\ Patricia Machado da Silva ${ }^{3}$ \\ Otavio Avila Pereira ${ }^{4}$ \\ Jose Antonio Bicca Ribeiro 5 \\ Leon Flores Cibeirab \\ Franciele Roos da Silva Ilha ${ }^{7}$ \\ Desire dos Santos Delias ${ }^{8}$ \\ Mariana Teixeira da Silva?
}

1 Mestrando em Educação Física. Universidade Federal de Pelotas (UFPel). Pelotas/ Rio Grande do Sul, Brasil. E-mail: ivanbremmoliveira@gmail.com

2 Doutora em Educação. Professora da Universidade Federal de Pelotas (UFPel). Pelotas/ Rio Grande do Sul, Brasil. E-mail: mrafonso.ufpel@gmail.com

3 Mestranda em Educação Física. Universidade Federal de Pelotas (UFPel). Pelotas/ Rio Grande do Sul, Brasil. E-mail: patriciamachadodasilva@hotmail.com

4 Licenciando em Educação Física. Universidade Federal de Pelotas (UFPel). Pelotas/ Rio Grande do Sul, Brasil. E-mail: oapereira@outlook.com

5 Doutorando em Educação. Universidade Federal de Pelotas (UFPel). Pelotas/ Rio Grande do Sul,Brasil. E-mail: zeantonio_bicca@outlook.com

6 Licenciando em Educação Física. Universidade Federal de Pelotas (UFPel). Pelotas/ Rio Grande do Sul, Brasil. E-mail: leonciba@gmail.com

7 Doutora em Educação. Professora da Universidade Federal de Pelotas (UFPel). Pelotas/ Rio Grande do Sul, Brasil. E-mail: francieleilha@gmail.com

8 Licencianda em Educação Física. Universidade Federal de Pelotas (UFPel). Pelotas/ Rio Grande do Sul, Brasil. E-mail: desire23frança@gmail.com

9 Mestranda em Educação Física. Professora no Colégio Sinodal Alfredo Simon. Pelotas/ Rio Grande do Sul, Brasil. E-mail: mariana_silva_12@yahoo.com.br

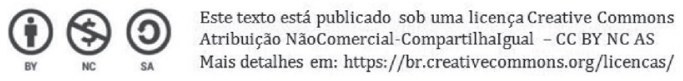




\title{
RESUMO
}

A presente pesquisa objetiva investigar as interfaces da produção científica acadêmica do subprojeto do Programa Institucional de Bolsas de Iniciação à Docência (PIBID) da Escola Superior de Educação Física da Universidade Federal de Pelotas (ESEF/UFPEL). Trata-se de uma pesquisa documental, que utilizou da análise de conteúdo da produção científica a partir do Congresso de Iniciação Científica (CIC/UFPEL) no período de 2013 a 2015. A partir dos achados foram extraídas duas categorias, a primeira com relação à formação inicial; e a segunda discutiu o impacto do PIBID na escola. Os resultados apontaram que as experiências de pesquisa, acenam para uma construção diferenciada no espaço da formação inicial, estágio e prática docente, revelando a complexidade da formação inicial; a segunda categoria revelou os impactos gerados pelo PIBID no contexto escolar oportunizando refletir e repensar a inovação e alternativas para o ambiente escolar.

Palavras-chave: Educação Física. Formação. Escola.

\section{ACADEMIC PRODUCTION AT SCIENTIFIC INITIATION: institutional Scholarship Program of Teaching Initiation as a knowledge production place}

\begin{abstract}
This research aims to investigate the interfaces of academic scientific production from subproject of Institutional Scholarship Program of Teaching Initiation of Physical Education High School. This is a documentary research witch used the scientific production content analysis from the Scientific Initiation Congress (CIC / UFPEL) from 2013 to 2015. From the findings were extracted two categories, the first related to teaching formation; and the second discussed the impact of PIBID at school. The results showed that the research experiences indicate a different building within the initial formation stage, revealing the complexity of teaching formation; the second category showed the impacts generated by PIBID in the school context providing opportunities to reflect and rethink innovation and alternatives to the school environment.
\end{abstract}

Keywords: Physical Education. Initial Formation. School. 


\section{PRODUCCIÓN ACADÉMICA EN LA INICIACIÓN CIENTífICA: el Programa Institucional de Bolsas de Iniciación a la Docencia como centro de producción del conocimiento}

\section{RESUMEN}

La presente investigación tiene como objetivo investigar la producción científica académica del Programa Institucional de Bolsas de Iniciación a la Docencia (PIBID) de la Escuela Superior de Educación Física de la Universidad Federal de Pelotas (ESEF/ UFPEL). Se trata de una investigación documental, que utilizó el análisis de contenido de la producción científica a partir del Congreso de Iniciación Científica (CIC/UFPEL) del periodo de 2013 a 2015. A partir de los resultados fueron extraídas dos categorías, la primera con relación a la formación inicial; y la segunda discutió el impacto del PIBID en la escuela. Los resultados de las experiencias de investigación apuntaron para una construcción diferenciada en el espacio de las prácticas supervisadas y prácticas docentes, revelando la complejidad de la formación inicial; la segunda categoría reveló los impactos generados por el PIBID en el contexto escolar permitiéndonos reflexionar y repensar en la innovación y alternativas para el ambiente escolar.

Palabras clave: Educación Física. Formación. Escuela.

\section{INTRODUÇÃO}

O Programa Institucional de Bolsas de Iniciação à Docência (PIBID), criado pelo Decreto n. 7.219 (BRASIL, 2010) e fomentado pela Coordenação de Aperfeiçoamento de Pessoal de Nível Superior (CAPES) propõe a articulação entre as Instituições de Ensino Superior (IES) e as escolas públicas de Educação Básica como forma de contribuir para a formação inicial de professores.

A CAPES tem buscado aperfeiçoar os procedimentos de acompanhamento de todos seus programas, inclusive do PIBID, exigindo relatórios técnicos fundamentados em análises de um conjunto de indicadores quantitativos e critérios qualitativos, o que, de certa forma, reforça a preocupação com a qualidade deste Programa.

Neste sentido, as IES que aderiram ao PIBID, têm buscado parcerias com as escolas para fomentar e discutir práticas inovadoras e que possibilitem o desenvolvimento da formação inicial dos acadêmicos que participam do projeto, como das escolas que os recebem, na medida podem receber futuros professores com ideias atualizadas, além da melhora de infraestrutura e materiais.

O objetivo desta pesquisa foi investigar as interfaces da produção científica acadêmica do PIBID, dentro do Congresso de Iniciação Científica $(\mathrm{CIC}){ }^{10}$ nos últimos três anos 
(2013 a 2015) no subprojeto da Escola Superior de Educação Física (ESEF), visto que este é o subprojeto da Universidade Federal de Pelotas (UFPel) que possui o maior número de bolsistas, contando com 68 alunos, 4 professores coordenadores e 9 professores supervisores de escola.

As linhas de ação deste subprojeto têm como mote oportunizar que o graduando participe de um processo que relaciona de modo indissociável a teoria e a prática educativa, contribuindo significativamente para a superação dos problemas comuns ao processo de ensino e aprendizagem na formação inicial (UFPel, 2013). Como exemplo de tal compreensão, fundamentamo-nos em Bracht e Caparroz (2007) quando os mesmos alertam que há uma série de interpretações dos problemas da didática e da pedagogia da educação física que dificultam uma (re)significação da didática neste campo de conhecimento. Segundo eles, uma das interpretações correntes e que dificultam tal (re)significação diz respeito ao papel da teoria pedagógica. A interpretação de que teorias (pedagógicas e didáticas) existem para serem aplicadas na prática é equivocada, pois as teorias não devem ser aplicadas na prática, elas precisam, ser modificadas pela prática. Eles trazem para reflexão um ditado popular, o qual é empregado como uma crítica aos processos educativos, que diz: "a teoria na prática é outra" e afirmam concordar com tal afirmativa, porém sem a ironia a ela atribuída, tendo em vista que a prática não é, não consegue ser, nem deveria tentar se constituir no espelho das teorias, seu ponto de aplicação. Elas são o ponto de partida, a fundamentação para se construir uma prática que será sempre singular, pois os envolvidos no processo, os espaços e os tempos escolares são específicos e estão em constantes transformações.

No que tange a especificidade da Educação Física, o Coletivo de Autores (1992) fundamenta os pressupostos adotados com as intervenções da Educação Física na escola. Esta é considerada uma prática pedagógica que tematiza formas de atividades expressivas corporais, entendidas como uma área de conhecimento denominada cultura corporal. Estas formas são os conteúdos da Educação Física, ou seja, jogos, esportes, capoeira, ginásticas e danças, considerados conhecimentos imprescindíveis para a compreensão do seu desenvolvimento sócio histórico e de suas significações.

Nas diretrizes do próprio Programa está a contraposição ao modelo de formação dicotômica que cria um distanciamento entre a escola e universidade. Segundo Barbosa e Dantas (2014), a dicotomia que perpassa a relação universidade e escola e, consequentemente entre teoria e prática, tem sustentação nas culturas formativas vigentes na nossa sociedade e na forma de produção e valorização do conhecimento dentro do espaço acadêmico.

Este mesmo autor acrescenta que a questão das diferentes culturas formativas no âmbito dos cursos de licenciaturas que envolvem o PIBID, requer cuidados para que a iniciação à docência não se confunda com a iniciação científica, a pesquisa deve fazer parte de todas as ações do PIBID. A defesa para que a pesquisa integre a formação inicial, centra-se na compreensão de que na graduação o aluno precisa aprender a construir reflexões sobre temas e questões relacionadas a sua formação e a sua prática como futuro professor.

Ao oferecer bolsas de iniciação à docência, o PIBID antecipa o vínculo do aluno com o futuro lócus de trabalho, pressupondo que a aproximação desses com as atividades de ensino nas escolas públicas, mediante a execução de um projeto institucional proposto 
por uma determinada IES, pode levá-los ao comprometimento e à identificação com o exercício do magistério.

Trazemos neste texto a discussão sobre os espaços híbridos de Zeichner (2010), como pano de fundo para fomentar o debate sobre a aproximação entre as escolas e as universidades, uma vez que este termo tem sido utilizado no campo educacional para romper com as formas hierárquicas de organização curricular e valorização cultural, dos conhecimentos práticos aos conhecimentos acadêmicos numa relação horizontal.

O hibridismo e o terceiro espaço:

[...] envolvem uma rejeição das binaridades tais como entre o conhecimento prático profissional e o conhecimento acadêmico, entre a teoria e a prática, assim como envolve a integração, de novas maneiras, do que comumente é visto como discursos concorrentes - em que uma perspectiva do isso ou aquilo é transformada num

ponto de vista do tanto isso, quanto aquilo (ZEICHNER, 2010, p.486).

Ainda segundo este autor, nesta concepção o conceito de terceiro espaço diz respeito à "criação de espaços híbridos nos programas de formação inicial de professores que reúnem professores da Educação Básica e do Ensino Superior, e conhecimento prático profissional e acadêmico em novas formas para aprimorar a aprendizagem dos futuros professores" (ZEICHNER, 2010, p.487)

Destacamos que a oportunidade do subprojeto na área da Educação Física (EF) por meio do PIBID tem sido de fundamental importância para uma formação mais qualificada para o licenciado, apoiando a elaboração de trabalhos de pesquisa na área, objetivando motivar os alunos bolsistas a sistematizarem cientificamente seus estudos e reflexões sobre os problemas enfrentados no cotidiano escolar socializando em eventos científicos (UFPel, 2013).

\section{METODOLOGIA}

Esta investigação caracteriza-se por ser uma pesquisa descritiva (GIL, 2008) que utilizou documentos como objeto de análise, também pode ser considerada como estudo do caso da Universidade Federal de Pelotas, a partir da análise de conteúdo da produção científica dos anais do Congresso de Iniciação Científica (CIC/UFPEL) no período de 2013 a 2015.

O foco das produções analisadas foi o Programa Institucional de Iniciação à Docência (PIBID) da universidade, a partir do subprojeto da Educação Física, que é constituído por duas áreas do conhecimento - ciências da saúde e ciências humanas. Foram considerados nesta pesquisa todos os trabalhos produzidos pelos acadêmicos vinculados ao PIBID/ESEF no período supracitado, independente da temática abordada.

Desenvolveram-se reuniões para a discussão dos procedimentos utilizados na seleção dos estudos, ou seja, uma "reunião de consenso" entre os autores (GOMES; CAMINHA, 2014; WIGGERS, 2015). É importante destacar que o objetivo deste trabalho 
foi constituir um quadro panorâmico, extraindo informações referentes ao impacto do PIBID para a formação em educação física e desta forma constituir subsídios para futuras discussões relacionadas a formação dos acadêmicos nesta perspectiva.

$\mathrm{Na}$ análise consideramos as temáticas que constituíam os trabalhos, bem como o campo de atuação dos acadêmicos e os resultados mais significativos apresentados por eles. A sistematização dos dados coletados foi feita tendo como norte a análise de conteúdo de Bardin (1977), de onde emergiram duas categorias-chave: O impacto do PIBID na formação inicial (estágios, prática docente e participação dos acadêmicos no PIBID); O PIBID e a escola (realidade escolar, implementação do programa, trabalho interdisciplinar).

Para elucidar a metodologia de coleta e análise dos dados, apresentamos um fluxograma que contém as informações referentes ao total de publicações encontradas, categorias que emergiram, bem como, os passos metodológicos.

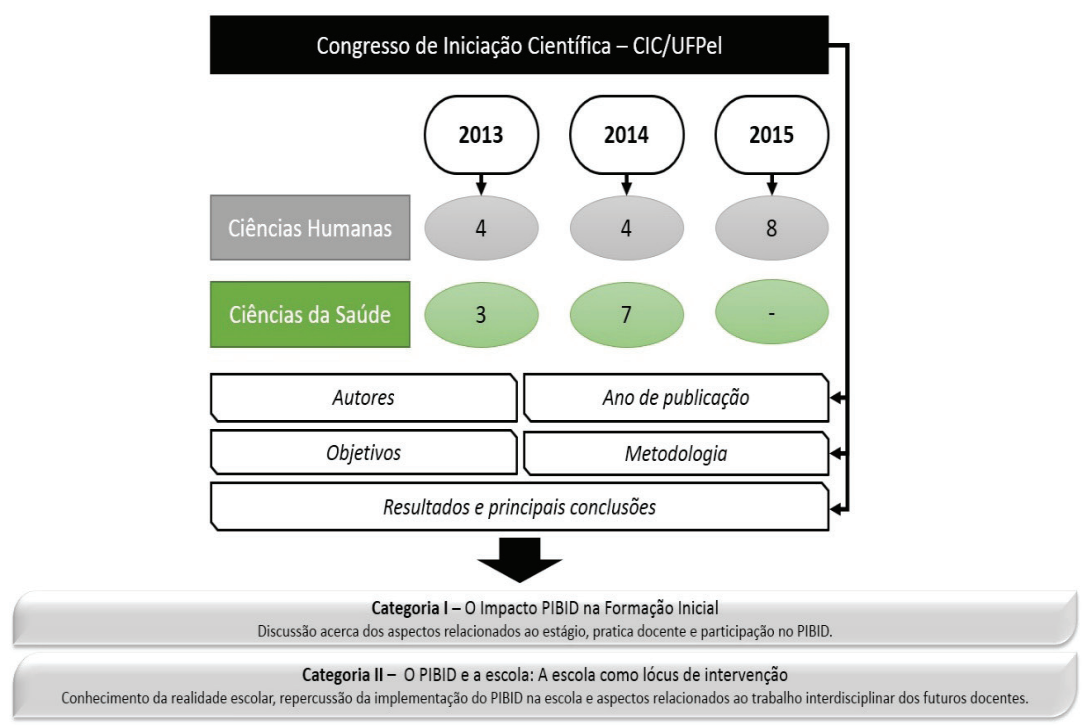

Figura 1 - Fluxograma das estratégias de coleta dos dados e categorização dos resultados

\section{RESULTADOS}

Para melhor compreensão dos dados originados a partir das buscas realizadas nos documentos do CIC, optamos por organizá-los em duas grandes categorias. A primeira categoria diz respeito ao impacto do PIBID na formação inicial, em que discutimos os aspectos relacionados ao estágio e a prática docente. Na segunda categoria foram analisados os trabalhos que buscavam investigar a escola como lócus de intervenção do Programa e seus desdobramentos, tendo como foco o conhecimento da realidade escolar e o trabalho interdisciplinar. 
Quadro 1 - Trabalhos referentes à formação inicial; estágio; prática docente.

\begin{tabular}{|c|c|c|c|c|c|}
\hline \multirow{2}{*}{ Categoria } & \multicolumn{3}{|c|}{$\begin{array}{l}\text { Total de } \\
\text { artigos }\end{array}$} & \multirow{2}{*}{$\begin{array}{l}\text { Temáticas } \\
\text { envolvidas }\end{array}$} & \multirow{2}{*}{$\begin{array}{l}\text { Principais } \\
\text { resultados }\end{array}$} \\
\hline & $\stackrel{n}{\text { D্ }}$ & $\underset{\text { ঠे }}{ \pm}$ & 윳 & & \\
\hline $\begin{array}{c}\text { Formação } \\
\text { Inicial }\end{array}$ & 5 & 4 & 5 & $\begin{array}{l}\text { - Impacto do PIBID } \\
\text { na formação dos } \\
\text { alunos; } \\
\text { - Aspectos da prática } \\
\text { docente; } \\
\text { - Contribuições do } \\
\text { PIBID para o estágio; } \\
\text { - Interface do } \\
\text { PIBID na evasão } \\
\text { de acadêmicos no } \\
\text { Programa; }\end{array}$ & $\begin{array}{l}\text { - Existe a aproximação da realidade da es- } \\
\text { cola com os conhecimentos advindos da } \\
\text { Universidade; } \\
\text { - O PIBID tem a possibilidade de prepara- } \\
\text { ção para o mercado de trabalho e cons- } \\
\text { trução dos conhecimentos necessários } \\
\text { para o trabalho docente; } \\
\text { - } \quad \text { Identificou-se a possibilidade de comple- } \\
\text { mentação curricular com a atuação na } \\
\text { escola, a partir do maior conhecimento } \\
\text { da realidade escolar; } \\
\text { - Existe uma maior preparação para a re- } \\
\text { alidade do estágio e contribuições para } \\
\text { formação do docente; } \\
\text { O PIBID possibilita a construção da } \\
\text { identidade profissional a partir do tra- } \\
\text { balho na escola além da superação das } \\
\text { dificuldades da docência desde o início } \\
\text { do curso; } \\
\text { Possibilidade de contato maior com o } \\
\text { trabalho docente, diferentemente do pe- } \\
\text { ríodo de estágio; } \\
\text { O PIBID auxilia na possibilidade da es- } \\
\text { colha do magistério como carreira pro- } \\
\text { fissional a partir do conhecimento do } \\
\text { ambiente da escola; } \\
\text { Maior aproximação entre teoria e prática } \\
\text { e oportunizaça da realização de pro- } \\
\text { cessos pedagógico; } \\
\text { - Construção de saberes docentes a partir } \\
\text { da prática no Programa; } \\
\text { A evasão de alguns acadêmicos do Pro- } \\
\text { grama foi reflexo da gestão do Programa, } \\
\text { e outros interesses profissionais fora da } \\
\text { docência; }\end{array}$ \\
\hline
\end{tabular}

Na categoria formação inicial destacamos que diante do aumento da carga horária dos estágios curriculares obrigatórios nos cursos de licenciatura em EF, a formação inicial está cada vez mais próxima do contexto da escola e das práticas pedagógicas. Esta mudança possibilita um maior contato do acadêmico com seu futuro campo de atuação profissional, ampliando os momentos de reflexão e práticas docentes no mesmo. 
Além disso, outras possibilidades de inserção à docência têm surgido em busca de estreitar ainda mais os laços entre universidade e escola, formação inicial e prática pedagógica, favorecendo a mobilização dos saberes que os acadêmicos têm construído em seus processos formativos.

O estudo de Oliveira et al. (2013), buscou averiguar as contribuições das vivências adquiridas no Programa para a formação dos futuros professores, a partir de um estudo descritivo, sobre o perfil do egresso segundo o Projeto Político Pedagógico do curso de Licenciatura em EF da UFPel. O estudo constatou que o PIBID contribuiu para que os pibidianos ampliassem seus conhecimentos sobre as práticas docentes, como metodologias e conteúdos, como também suas experiências como professor, unindo teoria e prática, inovando na busca para solução de problemas.

Um outro estudo relacionado com a formação e a prática pedagógica objetivou inferir sobre as contribuições das atividades realizadas pelos acadêmicos do curso EF no subprojeto PIBID/UFPel para a formação profissional e para a prática docente, analisando os relatórios finais do próprio projeto. Foi constatado que o subprojeto contribuiu para a ampliação da qualidade da formação dos alunos do curso que entraram em contato com o cotidiano escolar desde o início de sua graduação, oportunizando vivências e experiências importantes na aquisição de saberes docentes, e também mobilizando saberes provenientes de formação profissional para o magistério (OLIVEIRA et al., 2014).

Tardif (2002) nos ajuda a entender como ocorre a aquisição dos saberes docentes, que é uma construção por parte do professor ou futuro professor. Em sua compreensão, os saberes docentes se formam na confluência de vários saberes, os quais provem de diferentes fontes. Podem ser provenientes da sociedade, da instituição escolar, dos atores educacionais, das universidades, etc.

Além desta conceituação ampla do que são os saberes docentes, o autor distingue os diferentes tipos de saberes, de acordo com as fontes que lhes dão origem, são eles: os saberes da formação profissional que se referem ao saberes transmitidos pelas instituições de formação de professores, através das ciências da educação, relacionando-se com o trabalho pedagógico; os saberes disciplinares: são os saberes produzidos pelas disciplinas nas universidades, definidos e selecionados pela instituição; os saberes curriculares: são oriundos do contexto profissional que o professor atua, sistematiza-se através de documentos, por exemplo, que direciona as ações profissionais; e, os saberes experienciais: tornam-se os saberes próprios do professor e da sua vida educacional. Incorpora a experiência individual e coletiva (TARDIF, 2002).

Destacamos o trabalho de Moura et al. (2015) que também analisaram os processos formativos decorrentes da implantação das ações previstas no subprojeto, no âmbito do PIBID. A pesquisa foi de cunho qualitativo, do tipo estudo de caso e teve a utilização da análise documental. As reflexões elaboradas a partir das atividades e oficinas realizadas pelos bolsistas do PIBID revelaram conhecimentos variados sobre cultura e sociedade, tais como: a ocorrência do machismo e preconceito, desconhecimentos de práticas corporais importantes e preocupações com o cuidado do meio ambiente. Ao escapar, muitas vezes do lócus da especificidade da EF, esses conhecimentos mobilizados e construídos contribuem 
para a formação ampliada do futuro professor, permitindo que ele se reconheça como, integrante, atuante e responsável pela produção cultural da humanidade.

Assim, as vivências oportunizadas pelo PIBID, no que se referem ao estudo e preparação das intervenções, as práticas propriamente ditas e a avaliação do trabalho realizado contribuem de forma significativa para a formação do futuro professor consolidando conhecimentos que qualificam o trabalho docente na escola de Educação Básica. Além disso, o trabalho desenvolvido no âmbito do PIBID permite o discernimento sobre aspectos que "marcam" cada escola e conferem a ela características particulares no tocante a cultura do local onde estão inseridas (MOURA et al., 2015).

Nesta linha de pensamento, Tardif (2002) acrescenta que a prática profissional não é a simples aplicação de teorias elaboradas fora dela, mas um espaço original e relativamente autônomo de aprendizagem e de formação para os futuros professores, uma vez que a formação profissional é redirecionada para a prática e, por conseguinte, para a escola enquanto lugar de trabalho dos professores.

Ainda nesta categoria, foram analisados os trabalhos apresentados no $\mathrm{CIC}$ que faziam referência ao estágio. A importância dele se torna evidente, pelo fato de possibilitar a experiência prática e habilitar o futuro professor para a docência na educação básica, o que irá exigir o seu conhecimento multidisciplinar, bem como a caracterização das fases de crescimento e desenvolvimento do aluno até chegar aos procedimentos de ensino a serem adotados nas aulas (FERREIRA; KRUG, 2001).

Ainda nesse contexto, o período do estágio visa contribuir, de maneira fundamental, na formação do professor, uma vez que este momento tem a principal função de possibilitar a relação e reflexão teórico-prática na escola, concedendo benefícios no que diz respeito ao desenvolvimento dos mecanismos necessários para a aquisição dos conhecimentos básicos no exercício da profissão, assim como trazendo maior aproximação do graduando com o ambiente e a realidade escolar.

Pimenta e Lima (2004), sugerem que os cursos de formação devem possibilitar aos futuros professores formas de assimilar a complexidade das práticas profissionais, bem como o intuito de melhorar a preparação do profissional para o mercado que, posteriormente, o discente irá se inserir. Portanto, o estágio adquire grande importância nesta etapa de formação e se destaca como atividade preponderante para a construção do profissional, estabelecendo-se como um eixo central na formação de professores, dado que é através deste processo que o profissional poderá conhecer os aspectos indispensáveis tanto na sua formação profissional quanto na construção da identidade e dos seus saberes (PIMENTA; LIMA, 2004).

Todavia, observa-se que os discentes apenas fazem o contato efetivamente com a prática nas escolas a partir do $6^{\circ}$ semestre do curso de EF da UFPEL, quando realizam o seu primeiro estágio. O período em que os graduandos desenvolvem as suas potencialidades ocorre relativamente tarde e, para tanto, alguns projetos são desenvolvidos nas universidades, como é o caso do PIBID, que busca justamente essa ligação com as escolas e tem a intenção de preparar e conduzir os graduandos desde o início de suas práticas docentes. Logo, devido ao impacto visto por este Programa, muitos autores têm se dedicado a fortalecer discussões relacionadas ao estágio curricular e a influência do PIBID para esta etapa. 
Em termos de exemplo, encontra-se o estudo de Guterres, Matoso e Veronez (2015), em que se analisa a contribuição do PIBID para a melhoria na qualificação da prática pedagógica dos alunos do curso de graduação em Licenciatura em EF na disciplina de Prática de Estágio até o $5^{\circ}$ ano. Esse estudo contou com a participação dos bolsistas e ex-bolsistas do PIBID que já tinham realizado esta disciplina. Sendo assim, verificou-se que o Programa assegurou aos alunos benefícios na realização das atividades dentro da escola, refletindo proveitos no seu primeiro estágio. Para isso, os entrevistados relataram algumas competências do Programa, tais como: a importância das reuniões, as leituras e discussões, buscas por bibliografias, produção de artigos e participações em eventos científicos, que oportunizaram aos alunos o desenvolvimento das possibilidades enquanto docentes, adquirindo um embasamento além do que é colocado pela universidade normalmente, o que se deve ao conhecimento adquirido no cotidiano das escolas e o estímulo para a atuação na área de licenciatura.

Além disso, outras possibilidades de inserção à docência têm surgido em busca de estreitar ainda mais os laços entre universidade e escola, formação inicial e prática pedagógica, favorecendo a mobilização dos saberes que os acadêmicos têm construído em seus processos formativos. Em estudo realizado por Kolosque et al. (2014) tal fato pode ser evidenciado, na medida em que os bolsistas indicaram contribuições positivas do PIBID para a formação inicial como por exemplo, inserção na realidade do ambiente escolar, a possibilidade do trabalho interdisciplinar e a participação em eventos, seminários ou congressos.

O PIBID está contribuindo para o aumento dos conhecimentos atitudinais procedimentais e conceituais e específicos da EF e também das demais áreas integrantes do projeto e que são abordados na área interdisciplinar (SILVA et al., 2013). Em estudo realizado por Da Rosa et al. (2013), ficou evidenciado que 52,9\% dos bolsistas vinculados ao projeto já se consideram aptos para exercer atividades de enriquecimento cultural, trabalhar com diferentes conteúdos que forma a cultura corporal e diferentes abordagens sobre a mesma. Além disso, 94,1\% pretende seguir os estudos na pós-graduação (mestrado e doutorado), principalmente por julgarem importante o professor manter-se atualizado após a sua graduação.

É possível identificar ainda que o PIBID proporciona grandes contribuições no processo de formação inicial, sobretudo proporcionando a possibilidade de discutir aspectos alusivos à atuação na Educação Básica. Em estudo realizado por Silva et al. (2013), identificaram que 70,58\% dos bolsistas tem a capacidade de intervenção na Educação Básica, principalmente considerando as práticas docentes proporcionadas pelo PIBID. Além disso, $76,47 \%$ dos bolsistas adquiriram uma reflexão mais aprofundada a respeito dos conteúdos que compõem a área da EF escolar, e destacam a necessidade de trabalhar com mais elementos da cultura corporal, e não somente esporte coletivos como comumente acaba acontecendo na escola. No mesmo estudo, os participantes da pesquisa indicaram que a participação no programa oportuniza e estimula a participação acadêmica em eventos, contribuindo para sua formação. Em estudo realizado por Bonotto et al. (2014) e Lopes et al. (2013), resultados semelhantes foram encontrados, sendo que os bolsistas indicaram ter fortalecido suas experiências unindo a teoria com a prática. 
Um importante aspecto citado entre todos os estudos inseridos na pesquisa, diz respeito a motivação que o PIBID desperta nos bolsistas para a inserção na Educação Básica após formados, pois uma vez que tem o contato prévio com a realidade escolar, muitos acadêmicos indicam que conseguem vislumbrar as perspectivas profissionais do professor. No estudo realizado por Pereira et al. (2013), tal aspecto fica evidenciado, uma vez que $75 \%$ dos bolsistas indicaram uma motivação alta ou muito alta para permanecer atuando na Educação Básica após formados.

Entretanto, apesar de haverem contribuições positivas na participação dos alunos no PIBID, existem alguns desafios que também estão ligados a implementação do programa, e que dizem respeito a gestão institucional e características pessoais de cada acadêmico. Embora haja muitas contribuições e aproximação entre o trabalho realizado com o PIBID e a realidade da escola, alguns alunos mesmo estando em um curso de formação inicial para formação professores não tem identificação com a realidade profissional e abandonam o programa.

O trabalho apresentado por Silva, Silveira e Veronez (2015) encontrou como motivos que levam os bolsistas da EF a abandonarem o PIBID: a má gestão do subprojeto, o interesse por outras áreas de atuação dentro da EF e o desinteresse pela docência. Em uma universidade estadual do Paraná as motivações para o cancelamento das bolsas foi o término do curso (51\% - n: 111$)$ e cancelamento durante o curso (49\% - n: 107$)$. Dentre os motivos citados nesta segunda categoria estão fatores pessoais, como o desinteresse pela docência e o vínculo com outro programa (CASTRO, 2015), de maneira semelhante ao encontrado no subprojeto da EF.

Segundo Carvalho e Quinteiro (2013) o coordenador do PIBID/EF/UFSC relatou que umas das dificuldades encontradas foi a desistência de bolsistas, pois há muitas bolsas na universidade e os alunos acabam optando por aquelas que estão de acordo com sua organização e interesse pessoal e por aquelas que não tenham tantas demandas como o PIBID. Isso se assemelha ao encontrado no PIBID/EF/UFPel em que a extensa carga horária fez com que alunos desistissem do Programa, além dos interesses por outras áreas, como a pesquisa.

Nesta próxima categoria consideramos que a escola passa a ser o lócus de intervenção do PIBID, assim destacamos a importância de conhecer a realidade escolar, as repercussões da implementação deste Programa neste espaço, bem como os aspectos relevantes dos trabalhos interdisciplinares realizados.

Os trabalhos que buscavam o diagnóstico da escola, propiciaram o conhecimento sobre a organização escolar (níveis educacionais), os sujeitos inseridos neste contexto (funcionários, professores e alunos), estrutura física das escolas (salas de aula, quadras) e solicitam demandas melhores para estes espaços. 
Quadro 2 - Impacto do PIBID na escola.

\begin{tabular}{|c|c|c|c|c|c|}
\hline \multirow{2}{*}{ Categoria } & \multicolumn{3}{|c|}{$\begin{array}{l}\text { Total de } \\
\text { artigos }\end{array}$} & \multirow{2}{*}{$\begin{array}{l}\text { Temáticas } \\
\text { envolvidas }\end{array}$} & \multirow{2}{*}{$\begin{array}{l}\text { Principais } \\
\text { resultados }\end{array}$} \\
\hline & $\bar{n}^{n}$ & $\frac{ \pm}{\dot{2}}$ & ำ & & \\
\hline Escola & 2 & 7 & 3 & $\begin{array}{l}\text { - Possibilidades do } \\
\text { retorno do PIBID } \\
\text { para a escola; } \\
\text { - Interferência do } \\
\text { PIBID no panorama } \\
\text { da evasão na escola; } \\
\text { - Configuração } \\
\text { do espaço } \\
\text { escolar a partir da } \\
\text { implementação do } \\
\text { PIBID; }\end{array}$ & $\begin{array}{l}\text { - Com a participação no Programa, existe } \\
\text { uma maior possibilidade de atendimento } \\
\text { da demanda de aulas dentro da escola, a } \\
\text { partir de uma maior quantidade de bolsistas } \\
\text { intervindo em processos pedagógicos; } \\
\text { - A partir do PIBID, existe um maior conhe- } \\
\text { cimento da realidade escolar em contextos } \\
\text { específicos da própria comunidade, como } \\
\text { por exemplo elementos da própria cultura } \\
\text { do lugar; } \\
\text { O PIBID tem contribuído para o atendi- } \\
\text { mento de metas da política do IDEB a partir } \\
\text { do desenvolvimento dos alunos; } \\
\text { Foram identificados os desafios de realizar } \\
\text { um trabalho interdisciplinar dentro dos } \\
\text { seminários integrados, na medida em que } \\
\text { falta comunicação entre as disciplinas e o } \\
\text { modelo de ensino dentro da escola; } \\
\text { Identificou-se a interdisciplinaridade como } \\
\text { uma grande possibilidade de construção de } \\
\text { um novo conhecimento pelos alunos, mas } \\
\text { ao mesmo tempo existem dificuldades no } \\
\text { entendimento do conceito de interdiscipli- } \\
\text { naridade pelos bolsistas; }\end{array}$ \\
\hline
\end{tabular}

O diagnóstico é um documento válido para análise e conhecimento do espaço escolar e quanto mais amplo melhor. Este deve servir para verificar as principais causas de dificuldades mais frequentes.

Conforme dito anteriormente nesta categoria, ainda estão disponibilizados os resultados dos trabalhos que tratam das repercussões da implementação deste Programa para a escola, embora nos objetivos dele, não conste de forma direta os impactos esperados em relação aos alunos das escolas participantes do PIBID. Ao observarmos o Relatório de Gestão 2009- 2012, da Diretoria de Formação de Professores da Educação Básica (DED/ CAPES), a partir dos depoimentos, nos questionários e nos relatórios do PIBID, os bolsistas e as IES relatam e registram os seguintes impactos: a) elevação do desempenho dos alunos e, b) os bolsistas do PIBID atuantes na escola serviram de inspiração para a decisão de quais cursos de graduação poderiam ser seguidos.

Ao analisar as políticas públicas para a formação de professores no Brasil, Montandon (2012) afirma que o PIBID coloca os bolsistas em contato com os alunos da educação básica formando grupos de trabalho, de reflexões e compartilha experiências, ou seja, coloca 
o licenciando "no contexto para o qual está se formando, especialmente nos semestres iniciais" (MONTANDON, 2012, p.55).

No estudo de Rosa e Matos (2013), como repercussão do PIBID nos alunos da escola, foram notadas mudanças de atitude em relação às aulas e com os professores, valorização do aluno na escola e sua autovalorização, além do sentimento dos mesmos em fazerem parte do processo de ensino e de aprendizagem.

A partir de um dos trabalhos analisados sobre evasão escolar na E.F e as ações contributivas do PIBID, buscou-se avaliar o impacto das atividades do Programa nos alunos de uma escola estadual de ensino médio da cidade de Pelotas-RS, além de identificar e analisar sugestões feitas pelos alunos da escola. Também se esperava que a partir de tais dados, fosse possível inferir se as atividades desenvolvidas na escola elevaram a motivação dos alunos e, por conseguinte contribuíram na redução da evasão escolar.

Fernandes (2011) tratando da evasão da escolar aponta que as instituições escolares devem estar estruturadas dentro de um processo educativo em que todos os aspectos quantitativos e qualificativos, contínuos e espontâneos possam preparar cada cidadão socialmente dentro de todos os aspectos morais e intelectuais.

Foi possível verificar que um elevado número de alunos considerou as atividades do Programa benéficas para a escola e para si mesmos, além disso, os mesmos afirmaram ter interesse em seguir participando das atividades do PIBID, demonstrando ainda grande interesse em participar do Programa no futuro quando ingressassem na universidade. Estas intervenções na escola reforçam a importância de seu papel na construção de um cidadão consciente e crítico, motivado em suas ações dentro do ambiente escolar facilitando as conexões entre a escola e a universidade. Corroborando o objetivo destas intervenções veremos que:

Em relação ao abandono escolar salientamos o importante papel da escola, pois o(a) estudante está diretamente vinculado a ela em seu dia-a-dia. É necessário, antes de mais nada, que a escola tome todas as iniciativas que lhe cabem, visando a permanência do(a) estudante no sistema educacional, conscientizando-o(a) da importância da educação em sua vida e para seu futuro, mantendo contato frequente e direto com os pais ou responsáveis, enfatizando a responsabilidade destes na educação e na formação dos(as) filhos(as) (BRASIL, 2013, p.4).

Desta forma, ressaltamos a contribuição das ações do PIBID como um importante recurso para o combate à evasão escolar. As intervenções geradoras de motivação aos alunos constituem importante elemento para o processo de educação.

O projeto PIBID/UFPel tem na sua origem como eixo norteador os trabalhos interdisciplinares, essa ideia perpassa todas as práticas realizadas, tanto nas discussões na universidade, quanto nas práticas mediadoras no ambiente escolar. As pesquisas que tinham como mote a discussão da temática interdisciplinar buscavam compreender as possibilidades e desafios que o PIBID oportuniza para realização dos trabalhos interdisciplinares. Neste sentido os temas abordados por Duarte Junior et al. (2014) e Bittencourt et al. (2015) tinham como objetivo mapear o trabalho interdisciplinar que vinha ocorrendo na área especifica da EF apontando os enfrentamentos necessários. 
Na proposta de Fazenda (1998), a interdisciplinaridade ao propiciar o emergir da riqueza de ideias e ações sobre os saberes das diversas áreas do conhecimento traz a possibilidade de ampliação das perspectivas contidas em abordagem que possui potencial para uma aprendizagem significativa, necessária à educação contemporânea.

O PIBID ao priorizar em sua proposta de trabalho a interdisciplinaridade e a interlocução com as diferentes áreas de conhecimento da escola básica, corrobora com a afirmação de Barbosa (2014), quando este afirma que a formação para uma docência transformadora precisa ser baseada na constituição de uma identidade dialógica, por isso, no âmbito do PIBID, é fundamental cuidar para que não se continue formando professores identificados somente com as demandas específicas de sua área do conhecimento. A docência, o saber da e para a docência precisa resultar de uma forte identificação com o específico da área aplicado aos processos de ensino e aprendizagem. É necessário compreender que a formação de professores é o resultado da construção de estratégias colaborativas entre pares vindos de diferentes áreas e com diferentes formações.

Dentre as fragilidades apontadas nas pesquisas produzidas e apresentadas no $\mathrm{CIC}$, podemos perceber que há grande dificuldade em trabalhar dessa forma no âmbito da sala de aula e nas atividades cotidianas da escola, embora os alunos reconheçam a contribuição de cada área, é importante dissolvê-las em um tema comum. As dificuldades encontradas pelos alunos especialmente na Educação Física não estão ligadas diretamente à inserção da área no contexto do trabalho interdisciplinar, mas sim na dificuldade de pensar em conjunto com as demais áreas, visto o modelo de currículo fragmentado utilizado na educação básica que traz forte herança influenciando a forma de pensar dos alunos.

Ainda foi salientado que o conceito de interdisciplinaridade dos informantes é muito divergente e superficial. É sabido que a própria universidade em seus currículos de formação inicial não tem privilegiado o espaço para a formação interdisciplinar, os currículos são construídos de forma sistemática, muitas vezes não buscando as conexões possíveis com as diferentes áreas do conhecimento. Vários projetos interdisciplinares tiveram sucesso, entretanto o que foi realizado pouco tem a ver com o conceito de interdisciplinaridade. Trata-se da pluridisciplinaridade, pois há trocas de conhecimentos e experiências e não necessariamente uma unificação e homogeneização de saberes (VEIGA-NETO, 1996).

\section{CONCLUSÃO}

As experiências de pesquisa, aqui discutidas e apresentadas, embora embrionárias, acenam para uma construção diferenciada no espaço da formação inicial, assim ao retomar as questões apresentadas no texto, fica claro que existem duas grandes temáticas que tem gerado inquietações para pesquisa. A primeira temática traduzida pelos trabalhos referentes à formação inicial, considerando o estágio e a prática docente, revela a complexidade da formação em EF; a segunda categoria diz respeito aos trabalhos realizados para dar conta dos impactos gerados pelo PIBID no contexto escolar oportunizando refletir e repensar quais os reais impactos de um programa que se propõe a inovar e buscar alternativas para o ambiente escolar. 
As pesquisas aqui apresentadas são reveladoras da necessidade em pensar as possíveis conexões proporcionadas pela aproximação entre a universidade e a escola. Neste sentido finalizamos argumentando, que conforme previsto entre as linhas de ação deste Programa, os 26 trabalhos produzidos e apresentados no $\mathrm{CIC}$, oportunizaram bolsistas uma qualificação e reflexão sobre suas experiências antecipatórias como futuros professores e ainda como agentes de reflexão da própria prática durante sua formação inicial apropriando-se positivamente, tanto a partir das suas reflexões, quanto na experimentação de novas práticas interdisciplinares com cotidiano da escola. Por fim, sugerimos a realização de mais estudos que investiguem a aproximação e os tensionamentos entre teoria e prática produzidos no âmbito da graduação, mas que também fazem parte da formação dos estudantes. Sabemos que o presente estudo trata de um lócus bastante específico, mas ao buscar um mapeamento local, objetivamos construir pelo menos, uma nova lente para que se possa olhar de outra forma os aspectos relacionados à formação de professores em EF.

\section{REFERÊNCIAS}

BARBOSA, Marinalva Vieira. O PIBID e as culturas formativas no âmbito dos cursos de licenciaturas. IN: BARBOSA, Marinalva Vieira; DANTAS, Fernanda Borges A. (Orgs.). Reflexões sobre a Formação Inicial de Professores no PIBID. Campinas, SP: 2014. cap.1, p. 13-24.

BARBOSA, Marinalva Vieira; DANTAS, Fernanda Borges A. (org). Reflexões sobre a

Formação Inicial de Professores no PIBID. 1. ed. Campinas: Mercado de Letras, 2014. BARDIN, Laurence. Análise de conteúdo. Lisboa: Edições 70, 1977.

BITENCOURT, Giulia Specht et al. Interdisciplinaridade no PIBID: Dificuldades e Dilemas. IN: XXIV Congresso de Iniciação Científica da Universidade Federal de Pelotas. Pelotas. Anais... Pelotas: Universidade Federal de Pelotas, 2015.

BRASIL. Governo do estado do Paraná. Secretaria de Estado da Educação. Programa de combate ao abandono escolar. Curitiba, 2013.

. Decreto $\mathrm{n}^{\circ} 7.219$, de 24 de junho de 2010. Dispõe sobre o Programa Institucional de Bolsa de Iniciação à Docência - PIBID e dá outras providências. Diário Oficial da União, Brasília, DF, 25 jul. 2010.

BONOTTO, Anderson Lima et al. PIBID Educação Física: contribuições na formação inicial. IN: XXIII Congresso de Iniciação Científica da Universidade Federal de Pelotas. Pelotas. Anais... Pelotas: Universidade Federal de Pelotas, 2014.

BRACHT, V.; CAPARROZ, F. E. O tempo e o lugar de uma Didática da Educação Física.

Revista Brasileira de Ciências do Esporte, Colégio Brasileiro de Ciências do Esporte. Campinas, Autores Associados, v. 28, n. 2, p. 21-37, jan. 2007.

CARVALHO, Diana Carvalho de; QUINTEIRO, Jucirema. Entrevista com os coordenadores do PIBID-UFSC. EntreVer, Florianópolis, v. 3, n. 4, p. 322-341, jan/jun. 2013.

CASTRO, Luciana Paula Vieira de. O levantamento de algumas motivações para a desvinculação dos bolsistas do PIBID. IN: V Seminário Nacional Interdisciplinar em Experiências Educativas. Francisco Beltrão. Anais... Francisco Beltrão: Unioeste, 2015 
COLETIVO DE AUTORES. Metodologia de ensino da Educação Física. São Paulo: Cortez, 1992.

DA ROSA, Anderson Fernandes et al. Formação do professor de Educação Física: A influência do PIBID. IN: XXII Congresso de Iniciação Científica da Universidade Federal de Pelotas. Pelotas. Anais... Pelotas: Universidade Federal de Pelotas, 2013.

DUARTE JÚNIOR, Jair de Oliveira et al. A Interdisciplinaridade no Ambiente Escolar e a sua Aplicação. IN: XXIII Congresso de Iniciação Científica da Universidade Federal de Pelotas. Pelotas. Anais... Pelotas: Universidade Federal de Pelotas, 2014.

FAZENDA, Ivani Catarina Arantes. (Org). Didática e Interdisciplinaridade. $13^{\mathrm{a}}$ ed. Campinas: Papirus, 1998.

FERNANDES, Gislaine Hosana Araújo. Evasão escolar: um estudo para além dos muros escolares: 2011. 20f. Trabalho de conclusão de Curso (Gestão Pública Municipal) Centro de Ciências Sociais Aplicadas, UFPB, João Pessoa, 2011.

FERREIRA, Fabiane Fialho; KRUG, Hugo Norberto. A reflexão na Prática de Ensino em Educação Física. IN: KRUG, Hugo Norberto. (Org.). Formação de professores reflexivos: ensaios e experiências. Santa Maria: 2001.

GIL, Antonio Carlos. Métodos e técnicas de pesquisa social. $6^{\mathrm{a}}$ Ed. São Paulo: Atlas, 2008.

GOMES, Isabelle Sena; CAMINHA, Iraquitam de Oliveira. Guia para estudo de revisão sistemática: uma opção para as ciências do movimento humano. Movimento, Porto Alegre, v. 20, n. 1, p. 395-411, jan./mar. 2014.

GUTERRES, Samantha de Souza; MATOSO, Veridiana de Freitas; VERONEZ, Luiz Fernando Camargo. Influências do PIBID no estágio curricular supervisionado. IN: XIV Congresso de Iniciação Científica da Universidade Federal de Pelotas. Pelotas. Anais... Pelotas: Universidade Federal de Pelotas, 2015.

KOLOSQUE, Andrews Bruno et al. Formação do professor de Educação Física: A influência do PIBID. IN: XXIII Congresso de Iniciação Científica da Universidade Federal de Pelotas. Pelotas. Pelotas. Anais... Pelotas: Universidade Federal de Pelotas, 2014.

LOPES, Thiago Cardoso et al. PIBID: Contribuições na formação dos acadêmicos de Educação Física. IN: XXII Congresso de Iniciação Científica da Universidade Federal de Pelotas. Pelotas. Anais... Pelotas: Universidade Federal de Pelotas, 2015.

MONTANDON, Maria Isabel. Políticas públicas para a formação de professores no Brasil: os programas Pibid e Prodocência. Revista da ABEM, Londrina, v. 20, n. 28, p. 47-60, 2012.

MOURA, Patricia Quintana et al. Processos de Formação Docente no PIBID. IN: XXIV Congresso de Iniciação Científica da Universidade Federal de Pelotas. Pelotas. Anais... Pelotas: Universidade Federal de Pelotas, 2015.

OLIVEIRA, Calleb Rangel et al. Contribuições das Práticas Pedagógicas à Formação Inicial dos Bolsistas do PIBID Educação Física. IN: XXII Congresso de Iniciação Científica da Universidade Federal de Pelotas. Pelotas. Anais... Pelotas: Universidade Federal de Pelotas, 2013.

OLIVEIRA, Ivan Bremm et al. Formação e Prática Docente: uma Análise a partir do Programa Institucional de Bolsas de Iniciação à Docência. IN: XXIII Congresso de Iniciação Científica da Universidade Federal de Pelotas. Pelotas. Anais... Pelotas: Universidade Federal de Pelotas, 2014. 
PEREIRA, Otávio Ávila et al. PIBID e a formação inicial de professor de Educação Física. IN: XXII Congresso de Iniciação Científica da Universidade Federal de Pelotas. Pelotas. Anais... Pelotas: Universidade Federal de Pelotas, 2013.

PIBID-ESEF-UFPEL. Blog PIBID-ESEF-UFPEL. Disponível em: < http://pibidesefufpel. blogspot.com.br/ > . Acesso em:11 jun. 2014.

PIMENTA, Selma Garrido; LIMA, Maria Socorro Lucena. Estágio e Docência. São Paulo: Cortez, 2004. (Coleção docência em formação. Séries saberes pedagógicos).

SILVA, William Macedo et al. O impacto do PIBID na formação inicial de docentes em Educação Física na ESEF/UFPel. IN: XXII Congresso de Iniciação Científica da Universidade Federal de Pelotas. Pelotas. Anais... Pelotas: Universidade Federal de Pelotas, 2013.

SILVA, Patricia Côrrea; SILVEIRA, Leonardo Lemos; VERONEZ, Luiz Fernando Camargo. Fatores que levam os graduandos do curso de Licenciatura em Educação Física a ingressarem e a evadirem-se do Programa Institucional de Bolsas de Iniciação à Docência. IN: XIV Congresso de Iniciação Científica da Universidade Federal de Pelotas. Pelotas. Anais... Pelotas: Universidade Federal de Pelotas, 2015.

TARDIF, Maurice. Saberes docentes e formação profissional. 3. ed. Petrópolis: Vozes, 2002. UFPEL. Proposta Institucional PIBID - Edital no 61/2013. Disponível em: < http://wp.ufpel. edu.br/prg/programas/pibid/ > . Acesso em: 14 mai. 2014.

VEIGA NETO, Alfredo. Currículo, disciplina e interdisciplinaridade. Revista Brasileira de Ciências do Esporte, Campinas, v. 17, nº 2, 1996, p. 128-137, jan. 1996.

WIGGERS, Ingrid Dittrich et al. Um "raio-x" da produção do conhecimento sobre Educação Física Escolar: Análise de periódicos de 2006 a 2012. Movimento, Porto Alegre, v. 21, n. 3, p. 831-845, jul./set., 2015.

ZEICHNER, Ken. Repensando as conexões entre a formação na universidade e as experiências de campo na formação de professores em faculdades e universidade. Educação, Santa Maria, v. 35, n. 3, p. 479-504, maio/ago. 2010.

Recebido em: setembro/2016 Aprovado em: janeiro/2017 